рассматриваться как свободная и как инверсия. Некоторые изменения порядка слов изменяют синтаксические отношения, а с ними и весь смысл предложения, другие сочетают грамматическую и экспрессивную функции.

Возможны также изменения порядка слов, которые не меняют грамматического значения и не связаны с экспрессивностью или эмоциональностью, а имеют функциональностилистическую окраску. Экспрессивная или фукционально-стилистическая окраска инверсии характерна преимущественно для прозы, поскольку в стихах порядок слов подчиняется ритмико-интонационной структуре стиха, a расположение компонентов синтаксических конструкций относительно свободно. Использование того или иного порядка слов либо привлекает внимание слушателя к какому-либо обстоятельству, имеющему особую важность, либо показывает стремительность действий, либо создает иронию в предложении, либо указывает на эмоциональное состояние говорящего и т. д.

$$
* * *
$$

1. Арнольд И.В. Стилистика современного английского языка. - М.: Издательство: «Флинта», 2002. - 384 с.

2. Иванова И.П. и др. Теоретическая грамматика современного английского языка. - М.: Издательство: «Высшая школа, 1981. - 285 с.

3. Кобрина Н.А., Корнеева Е.А., Оссовская М.И., Гузеева К.А. Грамматика английского языка: Морфология. Синтаксис. - Издательство: «Союз», 2008. - 582с.

4. Шевякова В.Е. Современный английский язык: порядок слов, актуальное членение, интонация. - М.: Издательство: «Наука», 1980. - 380 с

5. Bradbury R. The Vocation. -Chicago: Advent, 1974. - 283 p.

6. $\quad$ Dickens Ch. Oliver Twist.- М.: Издательство: «Т8», 2016.- 412 c.

\title{
Кудзоева А.Ф. \\ К вопросу о пунктуационном оформлении однородных определений в осетинском языке
}

Институт истории и археологии Республики Северная Осетия-Алания (Россия, Владикавказ)

doi: 10.18411/trnio-09-2021-90

\section{Аннотация}

В статье рассматриваются вопросы определения однородности / неоднородности второстепенных членов предложения (в частности, определений) в осетинском языке, а также их пунктуационного оформления в зависимости от структуры предложения, стиля текста и интенций автора.

Ключевые слова: осетинский язык, принципы пунктуации, однородные определения, коммуникативно обусловленная пунктуация.

\section{Abstract}

The article discusses the issues of determining the homogeneity / heterogeneity of the secondary members of the sentence (in particular, definitions) in the Ossetian language, as well as their punctuation, depending on the structure of the sentence, the style of the text and the intentions of the author.

Keywords: ossetian language, principles of punctuation, homogeneous definitions, communicatively conditioned punctuation.

Введение. Как известно, знаки препинания выполняют функцию членения письменной речи, которое «не может быть передано ни морфологическими средствами, ни порядком расположения слов» [3]. В разных языках в основе такого членения лежат разные принципы: грамматический (или структурный, формально-грамматический), смысловой (семантический), интонационный и др. Разумеется, пунктуационная система не может строиться исключительно на одном принципе, чаще всего в ней в той или иной мере 
совмещаются несколько принципов, однако один из них бывает основным. В осетинском языке это, судя по нормативным правилам пунктуации, структурный принцип, когда знаки препинания являются формальными показателями синтаксической структуры предложения. В качестве второстепенного необходимо указать интонационный принцип, который применяется, чаще всего, при пунктуационном оформлении бессоюзного сложного предложения и приложений.

Структурный принцип - краеугольный камень осетинской пунктуации, опирающийся на представление об основных синтаксических понятиях (простое и сложное предложение, вводные и вставные конструкции, причастный оборот и др.), требующих четко установленного пунктуационного оформления. Однако структурный принцип не может «работать» без учета семантики синтаксической единицы и отсутствия/наличия экспрессии в тексте. Так, по структурному принципу конец предложения отмечается точкой, многоточием, вопросительным или восклицательным знаком. А вот выбор одного из этих знаков - в ведении семантического принципа: экспрессивно нейтральное повествовательное предложение заканчивается точкой, предложение с незавершенной, недосказанной мыслью многоточием. Восклицательный и вопросительный знаки не только отмечают конец предложения, но и сигнализируют об определенной интонации. Еще больше вопросов возникает при пунктуационном оформлении ряда определений с общим определяемым словом.

Целью работы является выявление признаков однородности / неоднородности определений в осетинском языке, формулирование правил постановки отделяющей запятой в ряду определений при общем определяемом слове.

Материалом исследования послужил текст сборника новелл и повестей современного осетинского писателя М.Р. Казиева «Завет Христа» [5].

Методологической базой исследования являются работы Н.С. Валгиной [2; 3], Н.К. Багаева [1] и др.

Об однородности определений в современном осетинском языке.

Правила осетинской пунктуации относительно устойчивы (вопрос о тенденциях развития или изменения пунктуации требует самостоятельного изучения). Однако могут ли они быть одинаковыми для всех типов письменной речи? Еще раз подчеркнув основополагающую роль структурного принципа, которое обеспечивает «беспрепятственное общение между пишущим и читающим» [2, с.19], отметим, что синтаксическое членение функционально разных письменных текстов - научного, художественного, официальноделового, публицистического - не может не отличаться. Если пунктуация научной и официально-деловой письменной речи максимально приближена к формальной, «хрестоматийной», учитывающей строение и значение отдельно взятого предложения, то публицистический и, особенно, художественный текст имеют свою специфику. «Связный текст диктует свои законы, свои правила. Пунктуация связного текста часто зависит от смысловых связей ряда синтаксических построений (предложений), объединенных единством мысли, общей стилистической направленностью, наконец, единым эмоциональноэкспрессивным настроем» [2, с.133].

Рассматривая предложение отдельно, вне контекста, не всегда можно с уверенностью обосновать необходимость тех или иных пунктуационных знаков. К примеру, Правила осетинской пунктуации [7] (далее - Правила) не дают основания для постановки отделяющей запятой между словами тохвселлад «усталый от войны» (здесь и далее перевод мой - А.К.) и серхуылм «угрюмый» в предложении Фкексестытсе йже кодта люмбынсег, сткей йсе тохвселлад, серхуым фылы йже фарстылжкй къуылмы бакодта [5, с.23] «Рассмотрел его внимательно, затем засыпал вопросами своего усталого от войны, угрюмого отца». Правила отмечают только один признак однородности определений: «Бæрæггæнæнтæ æмхуызон вæййынц, уыцы иу номдаримæ баст куы вæййынц æмæ йын йæ уыцы иу миниуæг (хуыз, ас, хъæд æ. а. д.) куы фæбæрæг кæнынц, уæд» [7, с.38]. («Определения бывают 
однородными, если оин связаны с одним существительным и определяют один и тот же его признак (цвет, размер, качество и т.д.»)

Не заостряяя внимания на некоторой некорректности приведенной формулировки однородности (определения обозначают признак предмета, a не существительного), приходится признать наши определения неоднородными: тохвсллад и серхуым

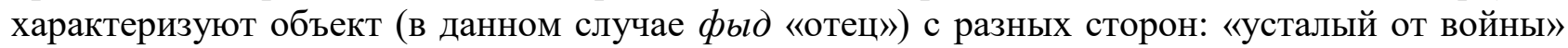
вовсе необязательно должен быть «угрюмым» - в зависимости от исхода войны он может испытывать и радость, и гордость, и удовлетворение. В то же время такое качество (или состояние), как угрюмость, не вытекает из общего состояние усталости воина. Но, в таком случае, мы имеем дело с неоднородными определениями, которые не должны отделяться запятой?

К сожалению, Правила не дают ответа и на этот вопрос, так как «Бæрæггæнæнтæ æмхуызон нæ вæййынц æмæ къæдзыгæй хицæнгонд нæ фæцæуынц, раззаг бæрæггæнæн номдары хицæнæй нæ, фæлæ йемæ баст фæстаг бæрæггæнæнимæ иумæ куы фæбæрæг кæны, уæд» [7, с.38]. («Определения бывают неоднородными и не отделяются запятыми, если первое из них определяет не отдельно существительное, а существительное вместе с последним определением»). В качестве иллюстрации неоднородности определений в Правилах приводится пример: Арф къседзехбын мкечъы иу люе хуыртсе хєессы хслд женебын тоесчbы...(Хеткегкаты Kъ.) [7, с.39]. «В глубоком овраге под скалой один человек носит камни в изломанной бездонной корзине».

Судя по единственному примеру, неоднородными являются определения, первое из которых выражено причастием (хселд от глагола хальын «ломать», «разбирать»), а второе относительным прилагательным. Совершенно понятно, что причастие относится не отдельно к существительному, а к сочетанию «прилагательное + существительное» и определения не могут быть однородными.

Однако оба определения из нашего примера - прилагательные, выражающие разные признаки предмета и, тем не менее, отделенные друг от друга запятой. Необходимость данного знака препинания диктуется как семантикой, так и интонацией предложения (ее устная форма явно требует паузы между словами тохвселлад и серхуым, распределяя смысловые акценты), что не дает основания усматривать в данном случае так называемую авторскую, то есть факультативную, пунктуацию. Возможно, дело в том, что пунктуационные правила, «рекомендуемые справочниками и учебниками, учитывают обычно отдельно взятое предложение, изолированное от других. Однако контекст, особенно художественный, в зависимости от интенций автора, диктует наличие пунктуационных знаков - своего рода сигналов семантических и интонационных нюансов. В таком случае можно говорить о контекстуально обусловленной пунктуации, принципиально отличной от факультативной, то есть необязательной. Контекстуально обусловленная пунктуация строго обязательна, потому что диктуется контекстом, необходима для точной передачи замысла автора. Она определяется не грамматикой текста, а, скорее, ее лексикой, обеспечивающей выразительность, образность, экспрессивность текста.

Приведенный выше пример взят из новеллы М. Казиева «Корзина». Произведение повествует о некоторых событиях из жизни алан - предков осетин, в том числе о бытовавшем в средние века обычае сбрасывать со скалы пожилых мужчин, не имеющих больше возможности участвовать в военных походах. Решение умереть таким образом принимали сами мужчины, больше смерти боявшиеся стать немощными, беспомощными. Весь текст новеллы эмоционально насыщен, изобилует образными определениями, эпитетами, объединенными высокой экспрессией произведения и намерением вызвать у читателя определенные мысли и чувства. В таком контексте каждое определение становится особенно значимым, нуждается в пунктуационном и интонационном выделении. Действительно, предложение Фкекестытюе йже кодта люембынсег, стхей йсе тохвселлад серхуылм фылды йсе фарстыткей къуылмы бакодта «Рассмотрел его внимательно, затем засыпал вопросами своего усталого от войны угрюмого отца» экспрессивно намного слабее 
и менее значимо в «диалоге» автора с читателем, чем вариант с отделенными запятой определениями.

Однако можно ли считать приведенный пример частным случаем контекстуально обусловленной пунктуации? Или все же постановки запятой требуют также формальнограмматический и семантический аспекты?

В отличие от Правил, грамматики современного осетинского языка указывают еще несколько признаков однородности определений. Так, в учебнике для вузов утверждается, что однородными могут быть определения, 1) если они выражены только качественными или только относительными прилагательными и находятся в одинаковых отношениях с определяемым словом; 2) если определение - прилагательное предшествует определению, выраженному причастным оборотом; 3) если между несколькими определениями возникают отношения градуальности [4, с.184].

В книге Н.К. Багаева указаны еще несколько признаков. Ученый совершенно справедливо называет однородными и определения, «характеризующие предмет с разных сторон. В этом случае контекст дает возможность для сближения выражаемых им признаков: общим признаком может служить отдаленное общее понятие, сходство производимого перечисленными признаками впечатления, внешний вид, общая положительная или отрицательная оценка и т.д.» [1, с.304-305], а также постпозитивные определения [1, с.305]. К примеру, с разных сторон характеризуют определяемые слово и бесспорно однородны определения в предложении Ави уылй джр тагъд скркъулжей жегуыдзжег, цжнкуыл, жегад зкерсдтимсе баддзсенис ксестоерты иур семсе йыл сылгоймсегтсе дсер худсгсей хсесдзыстыь ссехи? [5, c.19].«Или и он вскоре с поникшей головой будет сидеть рядом с младшими вместе с немощными, искалеченными, неуважаемыми (в осетинском языке все эти признаки передаются прилагательными - А.К.) стариками, и даже женщины будут смеяться над ним». Агуылдзсг, исенкуыл, сегад «немощные, искалеченные, неуважаемые» указывают на разные качества определяемого слова зжеседтсе «старики», однако в данном контексте они создают общее впечатление, взаимно дополняя друг друга: старики немощны, искалечены, но продолжают жить, не погибли в бою, как настоящие мужчины, и поэтому они сегад «неуважаемы».

Контекстуально обусловленные запятые между определениями.

Несомненно, следует внести в Правила (а также, разумеется, в грамматики осетинского языка) и другие признаки однородности определений.

Так, одно из определений может пояснять другое (как правило, препозитивное ему), значение которого очень общо, неопределенно. В таком случае можно говорить о практически полном отождествлении значений определений. Например: Мидсегсй, хуылфы йын женджр, бынбауинаг маст жегъатырсей сууильл, сау калмау, йже зсрдже [5, с.7]. «Внутри, в душе, подобно черной змее гложет его сердце другая, проклятая горечь». Сочетания сенджр маст «другая горечь» и бынбауинаг маст «проклятая горечь» равнозначны, между ними отношения пояснения.

Однородными следует считать и определения, значения которых контекстуально синонимичны. Хаестон, знжет бкехь късехты бын уседжер исты кодтаид [5, с.9]. «Под ногами боевых, агрессивных коней с ним что-нибудь случилось бы». Определения хсестон и знсет синонимичны только в определенном контексте: боевой конь не всегда агрессивен, а агрессиынм может быть не только боевой конь. Однако в этом контексте между ними знак равенства, и это служит средством увеличения экспрессивности теста, создания определенного настроения, выражения отношения автора к описываемым событиям.

Чаще всего однородны художественные определения, употребленные в переносном значении и тем самым повышающие образность повествования: Ксе ныл жеревсердзысты сже хъуынджын, зырзыргсенаг арм? [5, с.30]. «Когда они наложат на нас свою мохнатую, дрожащую руку?» Здесь речь идет о тревожном ожидании очередной агрессии со стороны грузинских националистов.

Контекстуально однородными являются так называемые пояснительные определения, когда второе определения поясняет первое. Следует отличать случаи 
пояснительных определений и определений с полным тождеством значений. В случае пояснительных отношений второе не тождественно первому, а только объясняет какой-то

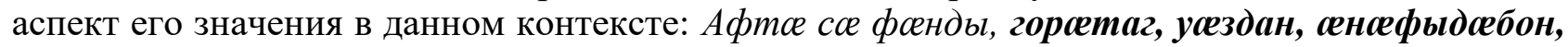

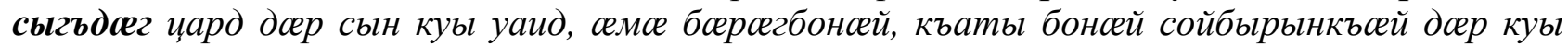
цсеуиккой $[5$, c.446]. «Они хотят, чтоб у них была городская, интеллигентная, беззаботная, чистая жизнь, и чтоб и в праздники, и в будни они ходили в масляными лицами». В этом контексте между определением горстаг «городской» и последующими словами можно поставить союз ома «то есть», так как определения усездан, сенсфылдсбон, сыгъджг поясняют, что имел в виду автор под «Городской жизнью». Формально в данном предложении запятые необязательно, так как поясняют признаки разной родовой принадлежности. Однако при отсутствии запятых предложение приобретает другой смысл:

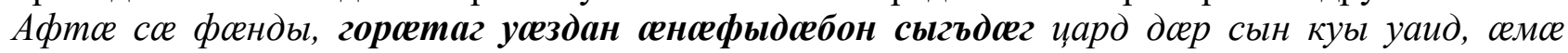
бжрсегбонсеи, къаты бонсей сойбырынкъсей джр куы ияєуиккой «Они хотят, чтоб у них была городская интеллигентная беззаботная чистая жизнь, и чтоб и в праздники, и в будни они ходили в масляными лицами» (интеллигентная беззаботная чистая жизнь может быть не только городской, но и какой-нибудь другой).

Контекстуально однородными становятся и определения, выраженные качественными или относительными прилагательными и характеризующие предмет с разных сторон, если этого требует стиль произведения (возможно, речь нужно вести об идиостиле автора) и, соответственно, его интонация и пунктуация: -Нже, нж, нж!.. - йсе тарбур, хуызивд,

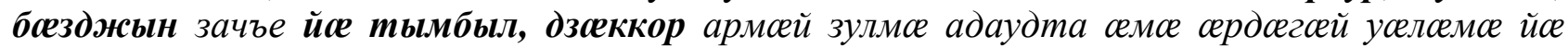
гуыр банкъуста [5, c.123]. «- Нет, нет, нет!.. - провел по своей темно-рыжей, выцветшей, густой бороде круглой, тяжелой ладонью и покачал свой корпус из стороны в сторону».

Наличие запятой между формально неоднородными определениями зависит и от порядка слов. Нормальным, нейтральным порядком расположения нескольких определений, выраженных качественными прилагательными, считается расположение непосредственно перед определяемым словом прилагательного со значением более постоянного признака. Если же определения выражены качественными и относительными прилагательными, то ближе к определяемому слову располагается относительное прилагательное. Определение, выраженное прилагательным, предшествует определению- причастию [6, с.23]. Нарушение обычного порядка слов приводит к интонационному и, соответственно, пунктуационному выделению определений: Згъслдысты йын, зжхх хъсщиулау чи 'мбжрзта, бжелесты уыцыь бур, $\boldsymbol{x y c ~ c ы ф т т о р т с е м . . . ~ « О н и ~ ( т о ~ е с т ь ~ с л е з ы ~ - ~ А . К . ) ~ к а т и л и с ь ~ н а ~ ж е л т ы е , ~ с у х и е ~ л и с т ь я ~}$ деревьев, устлавшие землю подобно одеялу...» Цы ацараза, уый нал зоны йсе тыхст, рсесугъд уд. «И не знает, что делать, ее испуганная, красивая душа».

Заключение. Таким образом, приходится констатировать, что в грамматиках современного осетинского языка приведен неполный перечень признаков однородности определений. Это отразилось и в Правилах осетинской пунктуации, соверешенно не учитывающих семантический, интонационный, коммуникативный аспекты пунктуационного оформления художественных текстов. Все это свидетельствует о необходимости переработки, дополнения и редактирования Правил осетинской пункуации.

$$
\text { *** }
$$

1. Багаев Н.К. Современный осетинский язык. Т.2. Орджоникидзе: Ир, 1982. 495 с.

2. Валгина Н.С. Актуальные проблемы современной русской пунктуации. Учебное пособие. М.: Высшая школа, 2004. 258 с.

3. Валгина Н.С. Синтантаксис современного русского языка: Учебник. М.: Агар, 2000. 416 c. http://www.hiedu.ru/e-books/xbook089/01/part-058.htm\#i7252

4. Джусоева К.Г., Дзодзикова З.Б., Цопанова Р.Г. Современный осетинский язык: учебное пособие для вузов. Владикавказ: Изд-во СОГУ, 2010. 307 с.

5. Казиев М.Р. Наказ Христа: новеллы, повести. Цхинвал: «ЦЫКУРА», 2016. 495 с.

6. Кудзоева А.Ф. Порядок слов и актуальное членение предложения в осетинском языке. Владикавказ: Изд-во СОГУ, 2002. 124 с.

7. Орфографические и пунктуационные правила осетинского языка. Владикавказ: Ир, 2004. 80 с. 